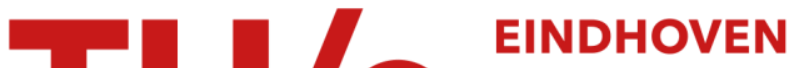

\section{Turnaround: exploring care relations in dementia through design}

\section{Citation for published version (APA):}

Houben, M., Lehn, B., van den Brink, N., Diks, S., Verhoef, J., \& Brankaert, R. (2020). Turnaround: exploring care relations in dementia through design. In CHI'20 Extended Abstracts, April 25-30, 2020, Honolulu, HI, USA [LBW351] (Conference on Human Factors in Computing Systems - Proceedings). ACM Press.

https://doi.org/10.1145/3334480.3382846

DOI:

$10.1145 / 3334480.3382846$

Document status and date:

Published: 25/04/2020

\section{Document Version:}

Typeset version in publisher's lay-out, without final page, issue and volume numbers

\section{Please check the document version of this publication:}

- A submitted manuscript is the version of the article upon submission and before peer-review. There can be important differences between the submitted version and the official published version of record. People interested in the research are advised to contact the author for the final version of the publication, or visit the $\mathrm{DOI}$ to the publisher's website.

- The final author version and the galley proof are versions of the publication after peer review.

- The final published version features the final layout of the paper including the volume, issue and page numbers.

Link to publication

\section{General rights}

Copyright and moral rights for the publications made accessible in the public portal are retained by the authors and/or other copyright owners and it is a condition of accessing publications that users recognise and abide by the legal requirements associated with these rights.

- Users may download and print one copy of any publication from the public portal for the purpose of private study or research.

- You may not further distribute the material or use it for any profit-making activity or commercial gain

- You may freely distribute the URL identifying the publication in the public portal.

If the publication is distributed under the terms of Article $25 \mathrm{fa}$ of the Dutch Copyright Act, indicated by the "Taverne" license above, please follow below link for the End User Agreement:

www.tue.nl/taverne

Take down policy

If you believe that this document breaches copyright please contact us at:

openaccess@tue.nl

providing details and we will investigate your claim. 


\section{Turnaround: Exploring Care Relations in Dementia Through Design}

\section{Maarten Houben}

Industrial Design, Eindhoven

University of Technology

m.houben1@tue.nl

\section{Benjamin Lehn}

Industrial Design, Eindhoven

University of Technology

b.v.lehn@student.tue.nl

\section{Noa van den Brink}

Industrial Design, Eindhoven

University of Technology

n.v.d.brink@student.tue.nl

\section{Sabeth Diks}

Industrial Design, Eindhoven

University of Technology

s.h.diks@student.tue.nl

Jasmijn Verhoef

Industrial Design, Eindhoven

University of Technology

j.k.verhoef@student.tue.nl

\section{Rens Brankaert}

Industrial Design, Eindhoven

University of Technology

\& Fontys University of

Applied Sciences

r.g.a.brankaert@tue.nl

Permission to make digital or hard copies of part or all of this work for personal or classroom use is granted without fee provided that copies are not made or distributed for profit or commercial advantage and that copies bear this notice and the full citation on the first page. Copyrights for third-party components of this work must be honored. For all other uses, contact the Owner/Author.

CHI'20 Extended Abstracts, April 25-30, 2020, Honolulu, HI, USA C) 2020 Copyright is held by the owner/author(s).

ACM ISBN 978-1-4503-6819-3/20/04.

https://doi.org/10.1145/3334480.3382846

\begin{abstract}
People with dementia often experience a lack of social engagement after moving from the home environment into long-term care. Professional caregivers aim to build social relations with residents in dementia care homes to empower and socially include them during everyday care. However, the natural imbalance between the caregiver and the cared-for positions the person with dementia in a passive role, making it difficult for them to initiate and build relations with caregivers. In this paper, we present 'Turnaround' as a design exploration into care relations and the potential role of design to support these relations. Turnaround is a musical interface to facilitate collaborative acts of music-making. Our preliminary results reveal how the role of resident and caregiver shifted towards equal partnership during the exploration and interaction with Turnaround. Furthermore, we argue that technologies should foster partnerships in care activities by facilitating shared forms of expression and reinforcement of agency.
\end{abstract}

\section{Author Keywords}

Caregivers; Care Practice; Dementia; Design; Sound.

\section{CSS Concepts}

- Human-centered computing $\rightarrow$ Empirical studies in HCI. 


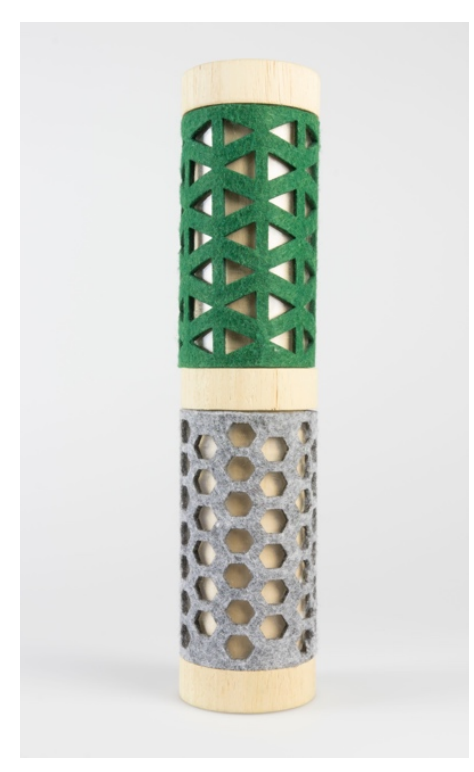

Figure 1: Turnaround is a collaborative musical interface to play sounds or music by turning the green or grey piece of fabric.

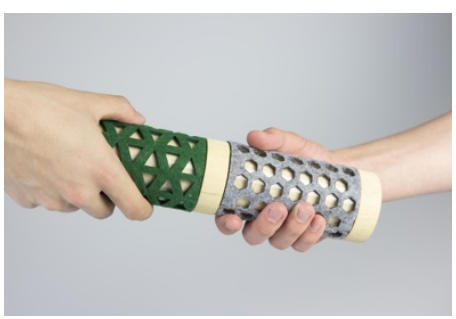

Figure 2: A person with dementia on one side and caregiver on the other side are holding and

interacting with Turnaround.

\section{Introduction}

Maintaining relationships and engaging in social interactions adds quality to the lived experience of dementia [13] and has a delaying effect on the progression of the condition [9]. However, the everyday life of people with dementia is often characterized by a lack of social engagement, negatively influencing the manifestation of the condition [15]. Therefore, professional caregivers who provide everyday care to people with dementia also connect emotionally and build relationships with residents in care homes [2]. This approach to engage and empower residents through social encounters is vital in providing Person-Centered Care (PCC) [3], which is a care strategy that aims to address the individual lived experiences of dementia.

However, in care practice, the person with dementia is still the receiver of care and often placed in a passive role during social encounters, while caregivers proceed with day-to-day care tasks [4]. Viewing people with dementia as less capable of taking the initiative in social interactions can cause an unbalanced relationship between the caregiver and the person with dementia [4]. This social imbalance makes it difficult to build and nurture interpersonal relationships, which are crucial for providing Person-Centered Care $[3,15]$. For these reasons, designers and researchers in $\mathrm{HCI}$ are interested in developing technologies to stimulate social interactions between residents and caregivers in dementia care homes. However, designers often overlook the relational imbalance as people with dementia still depend on caregivers to facilitate the use of these technologies in addition to providing care. An understanding is needed of how we can design technology to support equal partnership in care relations [16] and engaging activities where these established roles may change.

In this paper, we present 'Turnaround' (see Figure 1): a design exploration into relations of care in the context of dementia to investigate the role of design in facilitating an equal dialogue between residents and their caregivers in dementia care homes. Turnaround is a cylindrical musical interface to facilitate collaborative music-making, as shown in Figure 2. With this design artefact, we aim to 'turn around' existing perspectives on care relationships from viewing the person with dementia as a passive recipient of support to an active and equal partaker in their care relationship [15]. During an initial pilot study, seven pairs of residents and their caregivers from a dementia care home explored and interacted with the Turnaround artefact. The results of this pilot study provide preliminary insights into the existing care relations of the participants, and how the role of 'user' and 'facilitator' of technology can potentially shift towards an equal partnership. Based on these responses, we provide opportunities for future research on the design of technologies to support collaborative social activities and strengthen care relations in dementia care.

\section{Creativity, Sound, and Dementia in HCI}

Dementia is a complex condition that cannot be reduced to a fixed set of cognitive, social, or emotional deficits. Therefore, researchers in HCI are investigating how to design technologies to enrich the individual experience of dementia [13]. Participation and engagement in creative activities, such as art therapy or music sessions are known to enrich the everyday experiences of dementia [11]. Previous studies have explored various ways to facilitate the participation of 


\begin{tabular}{l|l} 
Setup 1 & \\
Green Side & Grey Side \\
\hline City Sounds & Abba \\
Sea Sounds & Frank Sinatra \\
Fireplace & Beethoven
\end{tabular}

Setup 2

\begin{tabular}{l|l} 
Green Side & Grey Side \\
\hline Guitar C4 & Piano C4 \\
Guitar E4 & Piano E4 \\
Guitar G4 & Piano G4
\end{tabular}

Table 1: Turnaround had two setups to play either recognizable sounds or musical chords.

\begin{tabular}{l|l}
$\begin{array}{l}\text { Caregiver } \\
\text { (F/M) }\end{array}$ & $\begin{array}{l}\text { Resident (F/M, } \\
\text { stage dementia) }\end{array}$ \\
\hline C1 (F) & P1 (F, moderate) \\
C1 (F) & P2 (F, moderate) \\
C2 (F) & P3 (F, late-stage) \\
C3 (F) & P4 (M, late-stage) \\
C4 (F) & P5 (F, late-stage) \\
C5 (F) & P6 (F, late-stage) \\
C6 (F) & P7 (M, late-stage)
\end{tabular}

Table 2: Overview of pairs of residents and caregivers. The residents were in a moderate to late stage of dementia, according to the care organization. We will refer respectively to the person with dementia as P\# and the caregiver as $\mathbf{C \#}$. people with dementia in these activities and how to leverage these insights into the design of technologies [12]. Facilitating creativity and improvisation, and stimulating participation open up new possibilities for design to promote a heightened sense of self-esteem and usefulness for persons with dementia [11]. For instance, auditory and tactile stimulation is already widely being used for their effect on evoking emotions by the recollection of memories [6] or stimulating social connection in a care setting [7]. In music sessions, the use of props and instruments enable people with dementia to feel like a performer instead of a 'patient' [14] as engaging with sound can stimulate creativity and improvisation [8]. Through these acts of creativity, people with dementia can express themselves without being limited by physical and cognitive deficits. By doing so in a group, engaging in meaningful activities allows new opportunities for recognition within care relationships $[6,14]$. Therefore, we will explore the care relations in dementia by providing a meaningful activity involving creative expression through sound.

\section{Turnaround: Collaborative Musical Interface} Collaboration and Connection

Turnaround invites professional caregivers and people with dementia to collaborate and engage in social interactions while making music together. The interface consists of two rotatable fabric shells around a wooden cylinder. The fabric parts need to be 'turned' or rotated in order to make music. Therefore, both participants are required to hold on to one part of the cylinder and turn it, and thus need to collaborate when using Turnaround to produce sounds and eventually create a musical soundscape. Turnaround establishes a physical connection between the two users, as they are required to hold the object together and move closer to each other in order to collaborate and use the device.

\section{Creativity}

Turnaround facilitates a creative activity involving music. By turning the cylindrical shells, different compositions of musical sounds can be played. Sounds are played when a user rotates the cylinder and stopped when the participant stops rotating. When a participant changes the direction of rotation, a new sound is played. All participants tested Turnaround in two different setups (see Table 1). In the first setup, music like 'Dancing Queen' by Abba and recognizable sounds such as a cozy fireplace were used. The second setup consisted of different musical chords that could be combined to make up a unique musical composition, with three different guitar sounds on one side and three piano sounds on the other. The sounds were produced through a Wizard of Oz technique [10], which is the simulation of the technological properties of a design prototype to convey the experience of using it.

\section{Empowerment}

Turnaround provides a safe and friendly interface for people with dementia, as music or sounds can be easily played by turning the pieces of soft fabric. In addition to turning, Turnaround allows other possibilities for interaction, as users could also tap, shake, or move the artefact. As we used the Wizard of Oz technique [10] to play sounds during the study, every interaction resulted in musical output. There was no right or wrong way of interacting with the artefact to facilitate open engagement. The interfaces for residents and caregivers are equal to foster engagement from both users and facilitate an equal partnership in using the artefact together. 


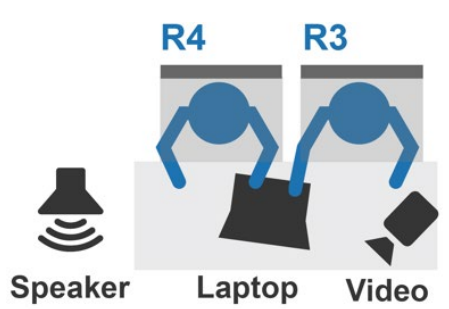

Speaker

Laptop Video

Camera

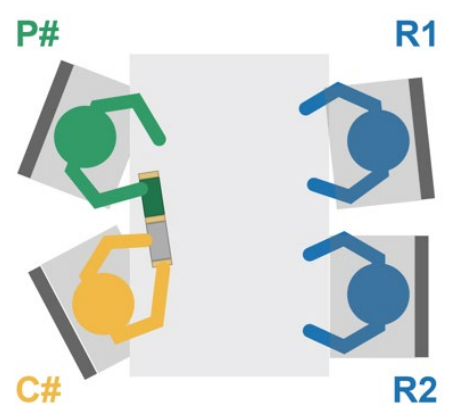

Figure 3: The research setup consisted of pairs of a person with dementia (P\#) and a caregiver (C\#) sitting at a table with the Turnaround prototype in one of the activity rooms of the care facility. Researchers R1 and $\mathbf{R 2}$ were sitting at the table to guide the activity and to provide initial instructions to the participants. $\mathbf{R 3}$ and $\mathbf{R} \mathbf{4}$ remained in the background and supported the Wizard of $\mathrm{Oz}$ technique by playing the sounds with a laptop connected to a speaker.

\section{Pilot Study Setup}

The goal of this pilot study was to explore the care relation of residents and their caregivers in a care home while interacting with Turnaround. The study was conducted at a residential long-term care facility for people with dementia. In total, seven people with latestage dementia, and six professional caregivers participated in this study (see Table 2 ).

The study consisted of three steps: 1 ) introduction of the experiment and artefact, 2) engaging with the artefact, and 3) exit interview. During the introduction, two researchers (R1, R2) had a casual conversation to get acquainted with the participants and make them feel comfortable. The researchers provided a brief explanation about Turnaround to the participants to stimulate learning and creative exploration. Next, the person with dementia and their caregiver explored and used Turnaround together. Both the first and second setup was tested in succession, in alternating orders for each session. Two researchers (R3, R4) used a laptop connected to a Bluetooth speaker to play the sounds as a result of the participants' interactions with

Turnaround, by using a Processing sketch for setup one and an online sample tool for setup two (see Figure 3). Afterwards, exit interviews were conducted with both the person with dementia and the caregiver to reflect on the activity and the artefact.

Before the study, the participants were extensively briefed about the study setup. Informed consent was granted by the caregivers and by the persons with dementia who participated in this study, who were also reminded that they could exit the study whenever desired with no explanation needed. Furthermore, the study setup was designed as a pleasant activity that facilitates social engagement and playful experiences. The qualified caregiver was present at all times to evaluate continuously if the person with dementia was still comfortable to continue participating in the study.

The activity was recorded on video to capture all communication and contact between the participants. The audio was transcribed verbatim, and the video footage was evaluated on body language, emotional responses, and changes in behavior or mood. All data were combined and analyzed by thematic analysis using an inductive approach [1]

\section{Preliminary Results}

Establishing a Dialogue

At the beginning of each session, the participants began to explore the artefact collaboratively. For example, as soon as P7 picked up Turnaround, he immediately started tapping the artefact, as shown in Figure 4. Exploring the functionalities of the artefact led to conversations between the caregiver and person with dementia about their background, preferences, and personalities, as participants linked the creative activity to aspects of their personal life. For instance, P4 was quick to analyze the sounds and melodies of setup one because of his background as a DJ: "there is a break when you stop twisting it, and for the rest, the song just stays the same." These conversations helped caregivers to learn more about the personal background and stories of the residents. For example, P7, who knew a lot about music, told the caregiver (C6) what kind of instruments he was hearing and how he thought the probe should be used: "I used to make something similar with GarageBand [Music software]." C6 was surprised at this reaction as she learned how P7 had much experience with playing and composing 


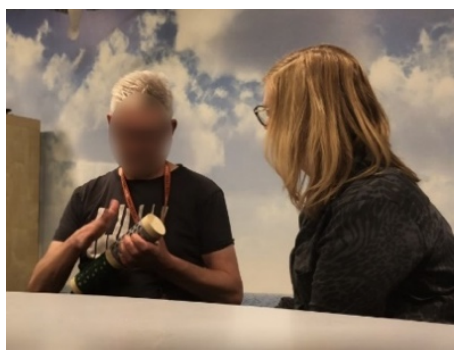

Figure 4: Participant is tapping Turnaround to discover different ways of using it.

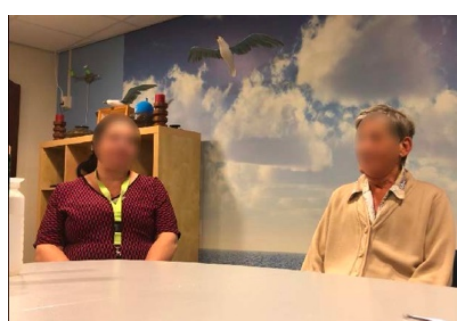

Figure 5: Caregiver (left) and resident (right) sitting apart at the beginning of the session.

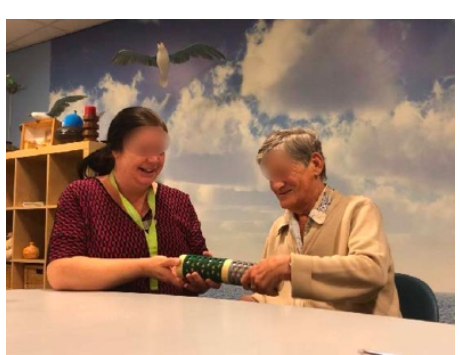

Figure 6: Participants moved closer to each other when using Turnaround. music: "You know a lot about that stuff!" Caregivers also shared their opinions and personal preferences: "I like listening to music and everything, but I am anything but a musical person." (C3) Whereas technologies tend to facilitate one-way questionings of the preferences of the person with dementia, the conversations triggered by Turnaround illustrate the potential value of facilitating a dialogue where residents and caregivers can become acquainted and build a more balanced care relation.

\section{Exploring Care Relationships}

The interface of Turnaround encouraged both the caregiver and the person with dementia to collaborate when using the artefact. C6 and P7 enjoyed doing this activity together: "Doing it together is nicer, isn't it?" asked $\mathrm{C} 6$ to P7, who responded: "Yeah, it has a different effect when turning it together." While being immersed in the activity, we could observe an increased connection or bond between the participants by analyzing body language and verbal responses. For instance, two pairs of participants (P3, C2; P6, C5) moved closer to each other while using the artefact, as shown in Figure 5 and Figure 6. Furthermore, participants verbally expressed their views on their care relation. For instance, C6 talked about other activities she usually did with P7: "I do like the aspect of interacting with it together, but for me, it does not have any additional value. It is mostly about keeping them busy." This quote gives a hint of how the caregiver perceives the person with dementia solely as a recipient of care. Conflicting statements of the person with dementia also reflected this complex nature of the care relationship, with P5 being discontent of being in the care home, but at the same time calling $\mathrm{C} 4$ her best friend: "Yes, she is my best friend, right? And I am going to be here for some years. Even though I do not really want to." At other times, the activity resulted in the caregiver complementing or admiring the person with dementia for their knowledge or their skills: "Oh... You are pretty musical, aren't you?" (C2) (see Figure 7) Actively involving the caregiver in the sessions with Turnaround seemed to benefit the experience of the resident and the caregiver as it offered opportunities to explore and enhance their relationship.

\section{Active Involvement}

At the beginning of the sessions, the caregivers and researchers mainly focused on the person with dementia, which sometimes made them feel awkward or as being 'in the spotlight' (see Figure 8). This mainly occurred at moments when participants were unsure about how to use the artefact and indicated a feeling of exclusion or being different: "Why can you do that, and I cannot?" (P5) As residents and caregivers became immersed in the interaction, the focus shifted towards the artefact and its peculiarities. This different focus was observable by changing body language and gestures, e.g., from introvert behavior to having an open attitude towards the artefact and the engagement. A similar change was observed in the verbal responses of the persons with dementia as they took a more active role in the exploration of Turnaround. For instance, P6 asked the caregiver: "What do you think?" C5 responded: "But what do you think?" as P6 immediately replied: "Well no, it is you and me. You also have to [answer]!" These questions of P6 towards her caregiver illustrated how in this particular case, the caregiver was considered an equal partner by the person with dementia with an equal contribution in interacting with and reflecting on the Turnaround design. 


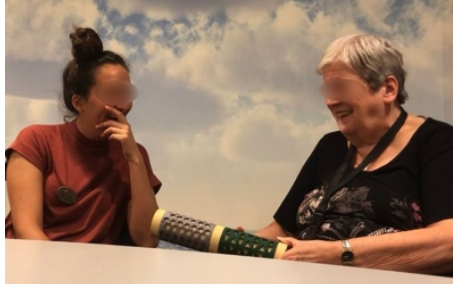

Figure 7: The caregiver listens to the stories of the resident.

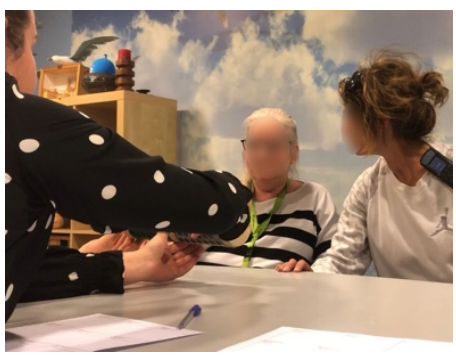

Figure 8: The initial focus was on the person with dementia at the beginning of the session, making them feel 'in the spotlight.' The focus shifted towards Turnaround during the artefact exploration.

\section{Acknowledgments}

We want to thank Myrte Thoolen, Serge Offermans, Loe Feijs,

Margo Lötters, and Bart

Hengeveld for their input, the staff of Pleyade, and Vitalis for facilitating the workshops and interviews, and the participants for their involvement.

\section{Opportunities for Future Research}

The responses observed during the collaborative activity with Turnaround reveal potential opportunities for technology and design to stimulate a sense of socia belonging by supporting people with dementia in taking an active role in the dialogue with the caregiver.

\section{Shared Forms of Expression}

The musical chords of setup two provided room for improvisation and musical expression by the participants in comparison to the sounds of setup one. This creative collaboration and conversation that arose in engagement with Turnaround indicated how a focus on remaining strengths, positive functions, and characteristics encourages active participation of people with dementia in moments of social contact [13]. Furthermore, the activity facilitated by Turnaround offered a fun, feasible, and exciting experience for anyone, regardless of their status or skills. Here we stress the importance of the subjective experience of the person with dementia in their immediate environment, with respect to their background and preferences. Therefore, the person with dementia needs to be considered as a competent and engaged individual, capable of taking an active role in social encounters in the care context [11]. Providing a common ground through interaction can be a way for people to realize how they are similar, included, and can collaborate with each other rather than only focus on the challenges of living with dementia. Future research should consider how such a common ground in design can support equal partnership in dementia.

Reinforcing Each Other's Agency

The activity being in the present and not relying on cognitive abilities also follows the idea of accepting a different reality rather than forcing the person with dementia to step into the reality of their environment, i.e., that of the caregivers and family members. Thereby, people with dementia can be seen as competent individuals with their own unique lived experience [5]. This approach makes it possible for both parties to enjoy the activity from their perspective. Next to that, a sense of individuality and empowerment presents a way to escape from the daily feeling of being taken care of and can instead provide a feeling of social belonging in the care home environment. Previous research $[4,9,15]$ has outlined the importance of social connections as well as the sensitive nature of the relationship with the caregiver for persons with dementia. With the preliminary results of our study, we suggest how collaborative activities involving creativity can be a way for people with dementia and their caregivers to support each other's agency in their care relations. Future research should consider how caregivers are thus not merely a care provider, but a partner with an active role in the care relation that is negotiated together with people with dementia.

\section{Conclusion}

In this paper, we illustrate how a collaborative activity, such as provided by Turnaround, can trigger responses that question existing roles in care relations. The complex conditions at play, such as the ambivalent relationship between the caregiver and the person with dementia or their individual needs, call for a careful and sensitive approach. Therefore, we argue how research on technology and dementia should consider shared forms of expression and reinforcement of social agency to foster and nurture the relationship between people with dementia and their caregivers. 


\section{References}

[1] Virginia Braun and Victoria Clarke. 2006. Using thematic analysis in psychology. Qual. Res. Psychol. 3, 2 (January 2006), 77-101.

DOI:https://doi.org/10.1191/1478088706qp063o

[2] Dawn Brooker. 2003. What is person-centred care in dementia? Rev. Clin. Gerontol. 13, 03 (August 2003), 215-222.

DOI:https://doi.org/10.1017/S095925980400108 $\mathrm{X}$

[3] Sam Fazio, Douglas Pace, Janice Flinner, and Beth Kallmyer. 2018. The Fundamentals of PersonCentered Care for Individuals With Dementia. Gerontologist 58, suppl_1 (January 2018), S10S19. DOI:https://doi.org/10.1093/geront/gnx122

[4] Mary Galvin. 2016. Supporting positive interactions within dementia relationships of care. PhD Thesis, University College Cork.

[5] James Hodge, Madeline Balaam, Sandra Hastings, and Kellie Morrissey. 2018. Exploring the Design of Tailored Virtual Reality Experiences for People with Dementia. In Proceedings of the $2018 \mathrm{CHI}$ Conference on Human Factors in Computing Systems (CHI '18), ACM Press, New York, New York, USA, Paper 514, 1-13.

DOI:https://doi.org/10.1145/3173574.3174088

[6] Maarten Houben, Rens Brankaert, Saskia Bakker, Gail Kenning, Inge Bongers, and Berry Eggen. 2019. Foregrounding Everyday Sounds in Dementia. In Proceedings of the 2019 on Designing Interactive Systems Conference - DIS '19, ACM Press, New York, New York, USA, 71-83. DOI:https://doi.org/10.1145/3322276.3322287

[7] Maarten Houben, Rens Brankaert, Saskia Bakker, Gail Kenning, Inge Bongers, and Berry Eggen. 2020. The Role of Everyday Sounds in Advanced Dementia Care. In Proceedings of the 2020 ACM Conference on Human Factors in Computing
Systems - (CHI '20), ACM Press, New York, New York, USA, Paper 450, 1-14.

DOI:https://doi.org/10.1145/3313831.3376577

[8] Gail Kenning, Alon Ilsar, Rens Brankaert, and Mark Evans. 2019. Improvisation and Reciprocal Design: Soundplay for Dementia. In Dementia Lab 2019. Making Design Work: Engaging with

Dementia in Context. D-Lab 2019. Springer Cham, 82-91. DOI:https://doi.org/10.1007/9783-030-33540-3_8

[9] Cunyoen Kim, Bailiang Wu, Emiko Tanaka, Taeko Watanabe, Kumi Watanabe, Wencan Chen, Sumio Ito, Rika Okumura, Tetsuaki Arai, and Tokie Anme. 2016. Association between a Change in Social Interaction and Dementia among Elderly People. Int. J. Gerontol. 10, 2 (June 2016), 7680.

DOI:https://doi.org/10.1016/J.IJGE.2016.03.006

[10] Scott R. Klemmer, Anoop K. Sinha, Jack Chen, James A. Landay, Nadeem Aboobaker, and Annie Wang. 2000. Suede: A Wizard of Oz Prototyping Tool for Speech User Interfaces. In Proceedings of the 13th annual ACM symposium on User interface software and technology (UIST '00), ACM, 1-10. DOI:https://doi.org/10.1145/354401.354406

[11] Amanda Lazar, Caroline Edasis, and Anne Marie Piper. 2017. A Critical Lens on Dementia and Design in HCI. In Proceedings of the $2017 \mathrm{CHI}$ Conference on Human Factors in Computing Systems (CHI '17), ACM Press, New York, New York, USA, 2175-2188.

DOI:https://doi.org/10.1145/3025453.3025522

[12] Amanda Lazar, Jessica L. Feuston, Caroline Edasis, and Anne Marie Piper. 2018. Making as Expression: Informing Design with People with Complex Communication Needs through Art Therapy. In Proceedings of the $2018 \mathrm{CHI}$ Conference on Human Factors in Computing Systems (CHI '18), ACM Press, New York, New 
York, USA, Paper 351, 1-16.

DOI:https://doi.org/10.1145/3173574.3173925

[13] Kellie Morrissey, John McCarthy, and Nadia Pantidi. 2017. The Value of Experience-Centred

Design Approaches in Dementia Research

Contexts. In Proceedings of the $2017 \mathrm{CHI}$

Conference on Human Factors in Computing

Systems (CHI '17), ACM Press, New York, New York, USA, 1326-1338.

DOI:https://doi.org/10.1145/3025453.3025527

[14] Kellie Morrissey, Gavin Wood, David Green, Nadia Pantidi, and John McCarthy. 2016. 'I'm a rambler, I'm a gambler, I'm a long way from home': The

Place of Props, Music, and Design in Dementia

Care. In Proceedings of the 2016 ACM Conference on Designing Interactive Systems (DIS '16), ACM Press, New York, New York, USA, 1008-1020. DOI:https://doi.org/10.1145/2901790.2901798

[15] Kristine Theurer, W. Ben Mortenson, Robyn Stone Melinda Suto, Virpi Timonen, and Julia Rozanova. 2015. The need for a social revolution in residential care. J. Aging Stud. 35, (December 2015), 201-210.

DOI:https://doi.org/10.1016/J.JAGING.2015.08.0 11

[16] David Unbehaun, Daryoush Daniel Vaziri, Konstantin Aal, Rainer Wieching, Peter Tolmie and Volker Wulf. 2018. Exploring the Potential of Exergames to affect the Social and Daily Life of People with Dementia and their Caregivers. In Proceedings of the 2018 CHI Conference on Human Factors in Computing Systems (CHI '18), ACM Press, New York, New York, USA, Paper 62 1-15.

DOI:https://doi.org/10.1145/3173574.3173636 